\title{
Robust Indirect Field Oriented Control of Induction Generator
}

\author{
S. Bozhko', S. Peresada ${ }^{2}$, S. Kovbasa ${ }^{2}$, M. Zhelinskyi ${ }^{2}$ \\ ${ }^{1}$ Faculty of Engineering, University of Nottingham, NottinghamNG7 2RD, United Kingdom \\ ${ }^{2}$ Department of Electrical Engineering, National Technical University of Ukraine "KPI", Peremogy av. 37, 03056 Kyiv, Ukraine \\ Corresponding author: Serhiy.Bozhko@nottingham.ac.uk
}

\begin{abstract}
The paper presents a novel robust field oriented vector control for induction generators. The proposed controller exploits the concept of indirect field orientation and guarantees asymptotic DC-link voltage regulations when DC-load is constant or slowly varying. An output-feedback linearizing Lyapunov's based technique is employed for the voltage controller design. Flux subsystem design provides robustness with respect to rotor resistance variations. Decomposition of the voltage and currentflux subsystems, based on the two-time scale separation, allows to use a simple controllers tuning procedure.

Results of comparative experimental study with standard indirect field oriented control are presented. It is shown that in contrast to existing solutions designed controller provides system performances stabilization when speed and flux are varying. Experimentally shown that robust field oriented controller ensures robust flux regulation and robust stabilization of the torque current dynamics leading to improved energy efficiency of the electromechanical conversion process. Proposed controller is suitable for energy generation systems with variable speed operation.
\end{abstract}

Keywords-induction generator, field-oriented control, variable speed energy generation.

\section{INTRODUCTION}

Variable speed electrical generation is an attractive solution for many energy plants: diesel, hydro and wind power stations [1], [2], ground vehicle, aerospace and naval power systems [3]. Main advantage of the variable speed generation is higher achievable energy efficiency of the primary mover and electrical generator.

The doubly-fed induction generator with vector control is an attractive solution for variable-speed energy generation applications with a converter connected between the stator and rotor [4]. The DFIG allows to produce constant-frequency electric power from a prime mover whose speed varies within a slip range, typically $20-30 \%$ of the DFIG synchronous speed. The converter needs only be rated for a fraction of the total output power, which depends on the allowable slip range [5]. AC-DC-AC power electronics configurations are commonly used for permanent magnet synchronous generator (PMSG) based systems [6], which are known as the most advanced generation systems for modern wind power stations. Nevertheless cost of PMSG is significantly higher than induction machine due to the use of rare-earth magnetic materials which have a very limited origin and their cost is continuously increasing. The tendency to reduce the use of expensive rare-earth magnets has driven a renewed interest for research into advanced design and control concepts for induction machine.
Simple and cheap induction machine generation system (IG), based on capacitor self-excitation [7], does not provide required accuracy of the voltage and frequency control.

An alternative approach is known as induction generation under field oriented control, reported in large number of publications since 1990th [1], [8], Fig.1. The standard control system structure of the field oriented generation is simple a copy of speed control system having indirect or direct field orientation with speed PI controller replaced by DC-bus PI voltage controller. The similarity of the two system is based on fact that outputs of the two controllers form the reference signal for electric machine torque and consequently for torque producing component of the stator current vector. Flux subsystems for motor and generation operation are the same and use the direct or indirect field orientation.

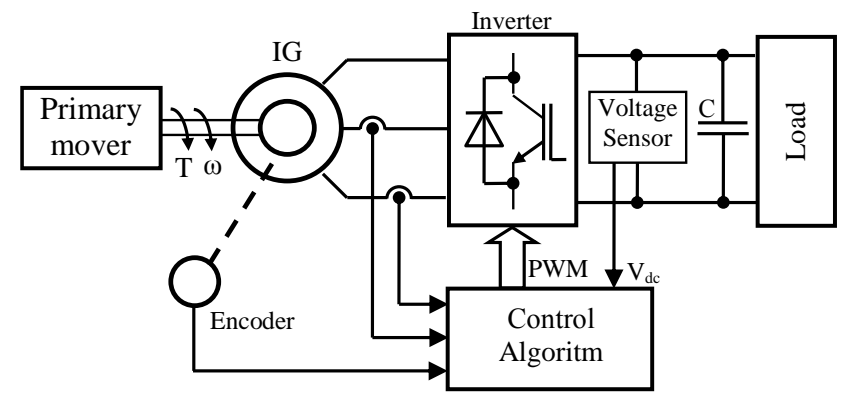

Fig. 1. Generation system structure

In [8] speed and flux variations are compensated in torque current computation, a novel nonlinear flux observer with saturation effect consideration is proposed. More recent publication [9] reports the system analysis based on some sort of linearized model and frequency domain approach. Active losses optimization is considered in [10]. The stability properties of the existing systems are not proved theoretically, so performances specifications are not available.

In [11] the authors proposed a new IG vector flux-voltage control algorithm based on output-feedback linearizing technique. In contrast to existing solutions the proposed feedback linearized controller provides linear DC link voltage error dynamics compensating for flux and speed variations and IG active losses. The linear equivalent structure of the voltage control loop allows to specify the dynamics performances of the voltage control loop.

The indirect field oriented controllers for induction machine are sensitive to variation of the rotor resistance. This problem is well investigated in literature and number of solutions are proposed on the base of robust and adaptive approaches [12], [13]. 
In this paper we developed a new robust indirect field oriented flux controller, which provides robust with respect to rotor resistance variations flux control improving both dynamic performance of the voltage control and energy efficiency of the electromechanical energy conversion. The results of the experimental studies are presented in order to demonstrate performances of the proposed control during different operation conditions. Comparison with a standard solution is presented as well.

This paper is organized as follows. The IG model and control problem formulation are given in Sections II. The fluxvoltage controller is designed in Section III. In Section IV the experimental results are reported followed by the Conclusions of the study.

\section{PROBLEM STATEMENT}

The standard two-phase model of electrical part of symmetrical induction generator, under the assumptions of linear magnetic circuits and balanced operating conditions, is represented in an arbitrary rotating reference frame (d-q) as [12]

$$
\begin{aligned}
& \dot{\mathrm{i}}_{\mathrm{d}}=-\gamma \mathrm{i}_{\mathrm{d}}+\omega_{0} \mathrm{i}_{\mathrm{q}}+\alpha \beta \psi_{\mathrm{d}}+\beta \omega \psi_{\mathrm{q}}+\sigma^{-1} \mathrm{u}_{\mathrm{d}}, \\
& \dot{\mathrm{i}}_{\mathrm{q}}=-\gamma \dot{\mathrm{i}}_{\mathrm{q}}-\omega_{0} \mathrm{i}_{\mathrm{d}}+\alpha \beta \psi_{\mathrm{q}}-\beta \omega \psi_{\mathrm{d}}+\sigma^{-1} \mathrm{u}_{\mathrm{q}}, \\
& \dot{\psi}_{\mathrm{d}}=-\alpha \psi_{\mathrm{d}}+\left(\omega_{0}-\omega\right) \psi_{\mathrm{q}}+\alpha \mathrm{L}_{\mathrm{m}} \mathrm{i}_{\mathrm{d}}, \\
& \dot{\psi}_{\mathrm{q}}=-\alpha \psi_{\mathrm{q}}-\left(\omega_{0}-\omega\right) \psi_{\mathrm{d}}+\alpha \mathrm{L}_{\mathrm{m}} \mathrm{i}_{\mathrm{q}}, \\
& \dot{\varepsilon}_{0}=\omega_{0}, \varepsilon_{0}(0)=0, \\
& \mathrm{P}_{\mathrm{s}}=-(3 / 2)\left(\mathrm{u}_{\mathrm{d}} \mathrm{i}_{\mathrm{d}}+\mathrm{u}_{\mathrm{q}} \mathrm{i}_{\mathrm{q}}\right),
\end{aligned}
$$

where $\mathbf{u}=\left(\mathrm{u}_{\mathrm{d}}, \mathrm{u}_{\mathrm{q}}\right)^{\mathrm{T}}$ is the control vector of stator voltages, $\mathbf{i}=\left(\mathrm{i}_{\mathrm{d}}, \mathrm{i}_{\mathrm{q}}\right)^{\mathrm{T}}, \boldsymbol{\psi}=\left(\psi_{\mathrm{d}}, \psi_{\mathrm{q}}\right)^{\mathrm{T}}$ denote stator current and rotor flux vectors, $\omega$ is the rotor speed. Subscripts $d$ and $q$ stand for vector components in the $(\mathrm{d}-\mathrm{q})$ reference frame, $\varepsilon_{0}$ is the angular position of the $(\mathrm{d}-\mathrm{q})$ reference frame with respect to a fixed stator reference frame (a-b), where physical variables are defined; $\mathrm{P}_{\mathrm{s}}-$ active power produced by IG.

Positive constants related to the electrical and mechanical parameters of the IM are defined as follows:

$$
\alpha=\frac{\mathrm{R}_{2}}{\mathrm{~L}_{2}}, \sigma=\mathrm{L}_{1}\left(1-\frac{\mathrm{L}_{\mathrm{m}}^{2}}{\mathrm{~L}_{1} \mathrm{~L}_{2}}\right), \beta=\frac{\mathrm{L}_{\mathrm{m}}}{\sigma \mathrm{L}_{2}}, \gamma=\frac{\mathrm{R}_{1}}{\sigma}+\alpha \mathrm{L}_{\mathrm{m}} \beta,
$$

where $\mathrm{R}_{1}, \mathrm{R}_{2}, \mathrm{~L}_{1}, \mathrm{~L}_{2}$ are stator/rotor resistances and inductances, respectively, $\mathrm{L}_{\mathrm{m}}$ is the magnetizing inductance. One pole pair is assumed without loss of generality.

Transformed variables in (1) are defined according to

$$
\begin{aligned}
& \mathbf{x}_{\mathrm{dq}}=\mathbf{e}^{-\mathrm{J} \varepsilon_{0}} \mathbf{x}_{\mathrm{ab}}, \\
& \mathbf{x}_{\mathrm{ab}}=\mathbf{e}^{\mathrm{J} \varepsilon_{0}} \mathbf{x}_{\mathrm{dq}},
\end{aligned}
$$

where $\mathbf{e}^{-\mathbf{J} \varepsilon_{0}}=\left[\begin{array}{cc}\cos \varepsilon_{0} & \sin \varepsilon_{0} \\ -\sin \varepsilon_{0} & \cos \varepsilon_{0}\end{array}\right], \mathbf{J}=\left[\begin{array}{cc}0 & -1 \\ 1 & 0\end{array}\right], \mathbf{x}_{\mathrm{yz}}$ stands for two-dimensional voltage, flux and stator current vectors.

Produced by IG electrical power $\mathrm{P}_{\mathrm{s}}$ is transferred to DClink by IGBT inverter. Under assumption of ideal inverter without loses the DC-link power $\mathrm{P}_{\mathrm{dc}}$ is equal to generation power $\mathrm{P}_{\mathrm{s}}$. In this case DC-link voltage $\mathrm{V}_{\mathrm{dc}}$ dynamics is described by

$$
\begin{gathered}
\dot{\mathrm{V}}_{\mathrm{dc}}=\mathrm{C}^{-1}\left(\mathrm{i}_{\mathrm{dc}}-\mathrm{i}_{\mathrm{L}}\right), \\
\mathrm{i}_{\mathrm{dc}}=\mathrm{P}_{\mathrm{dc}} / \mathrm{V}_{\mathrm{dc}}=\mathrm{P}_{\mathrm{s}} / \mathrm{V}_{\mathrm{dc}},
\end{gathered}
$$

where $\mathrm{C}$ - is DC-link capacitance, $\mathrm{i}_{\mathrm{dc}}-$ DC-link current from inverter, $\mathrm{i}_{\mathrm{L}}$ - load current.

Consider the IG and DC-link models (1), (4) and assume that:

A1. The stator currents, rotor speed and load current are available for measurement. Rotor speed $\omega>0$. All generator parameters and DC-link capacitance are known and constant.

A2. The DC-link voltage reference $V_{d c}^{*}>0$ is constant.

Under these assumptions, the control problem is to design a flux-voltage controller which guarantees the following control objectives:

CO1. Asymptotic voltage regulation with all internal signals bounded, i.e.

$$
\lim _{\mathrm{t} \rightarrow \infty} \tilde{\mathrm{V}}_{\mathrm{dc}}=0,
$$

where $\tilde{\mathrm{V}}_{\mathrm{dc}}=\mathrm{V}_{\mathrm{dc}}-\mathrm{V}_{\mathrm{dc}}^{*}$ is voltage regulation error.

CO2. Asymptotic flux regulation:

$$
\lim _{\mathrm{t} \rightarrow \infty} \tilde{\psi}=0,
$$

where $\tilde{\psi}=\psi-\psi^{*}-$ is a flux regulation error, $\psi-$ flux vector magnitude, $\psi^{*}>0-$ constant flux reference.

CO3. Asymptotic field orientation, i.e.

$$
\lim _{\mathrm{t} \rightarrow \infty} \psi_{\mathrm{q}}=0 \text {. }
$$

CO4. Robustness to rotor resistance variations.

The following sections report the proposed solution to the formulated control problem.

\section{CONTROLLER DESIGN}

\section{A. Robust flux-current field oriented controller}

Let consider indirect field oriented control algorithm for system (1), which consists of

- flux controller

$$
\begin{aligned}
& \quad \dot{\varepsilon}_{0}=\omega_{0}=\omega+\alpha \mathrm{L}_{\mathrm{m}} \mathrm{i}_{\mathrm{q}} / \psi^{*}+\gamma_{1} \beta \omega \tilde{\mathrm{i}}_{\mathrm{d}} / \psi^{*}+\gamma_{2} \beta \omega \tilde{\tilde{\mathrm{i}}_{\mathrm{d}}} / \psi^{*}, \\
& \quad \mathrm{i}_{\mathrm{d}}^{*}=\left(\alpha \psi^{*}+\dot{\psi}^{*}\right) / \alpha \mathrm{L}_{\mathrm{m}}, \\
& \text { - d-axis current observer }
\end{aligned}
$$

$$
\dot{\hat{i}}_{d}=-\gamma \hat{i}_{d}+\omega_{0} i_{q}+\alpha \beta \psi^{*}+\sigma^{-1} u_{d}+k_{1} \tilde{i}_{d},
$$

- current controllers

$$
\begin{aligned}
& \mathrm{u}_{\mathrm{d}}=\sigma\left(\gamma \mathrm{i}_{\mathrm{d}}^{*}-\omega_{0} \mathrm{i}_{\mathrm{q}}-\alpha \beta \psi^{*}-\mathrm{k}_{\mathrm{id}} \tilde{\mathrm{i}}_{\mathrm{d}}+\mathrm{z}_{\mathrm{d}}\right), \\
& \dot{\mathrm{z}}_{\mathrm{d}}=-\mathrm{k}_{\mathrm{ii}} \tilde{\mathrm{i}}_{\mathrm{d}}, \\
& \mathrm{u}_{\mathrm{q}}=\sigma\left(\gamma \mathrm{i}_{\mathrm{q}}{ }^{*}+\omega_{0} \dot{\mathrm{i}}_{\mathrm{d}}+\beta \omega \psi^{*}-\mathrm{k}_{\mathrm{iq}} \tilde{\mathrm{i}}_{\mathrm{q}}+\mathrm{z}_{\mathrm{q}}\right), \\
& \dot{\mathrm{z}}_{\mathrm{q}}=-\mathrm{k}_{\mathrm{ii}} \tilde{\mathrm{i}}_{\mathrm{q}},
\end{aligned}
$$

where $\tilde{i}_{d}=i_{d}-i_{d}^{*}$ and $\tilde{i}_{q}=i_{q}-i_{q}^{*}$ are current tracking errors, $i_{d}^{*}, i_{q}^{*}-$ are references for $i_{d}$ and $i_{q}$ currents respectively, $\tilde{\tilde{i}}_{\mathrm{d}}=\mathrm{i}_{\mathrm{d}}-\hat{\mathrm{i}}_{\mathrm{d}}$ is $\mathrm{d}$-axis current observation error, $\mathrm{z}_{\mathrm{d}}, \mathrm{z}_{\mathrm{q}}-$ integral 
terms of current controllers, $\left(\mathrm{k}_{\mathrm{id}}, \mathrm{k}_{\mathrm{iq}}\right)$ are the current controller's proportional gains, $\mathrm{k}_{\mathrm{ii}}$-current controller's integral gains, $\left(\gamma_{1}, \gamma_{2}\right)$ - correction coefficients, $\mathrm{k}_{1}-$ current observer gain.

It is important to note that the correction term $\gamma_{1} \beta \omega \tilde{\mathrm{i}}_{\mathrm{d}} / \psi^{*}+\gamma_{2} \beta \omega \tilde{\tilde{\mathrm{i}}} \mathrm{d} / \psi^{*}$ provides the closed loop properties for flux subsystem and therefore the controller (8) - (11) potentially has robustness properties with respect to rotor resistance variations at non-zero machine speed. This property will be proven by results of the experimental study.

Let assume that $i_{\mathrm{q}}^{*}$ and $i_{\mathrm{d}}^{*}$ are slowly varying signal, so that $\dot{i}_{\mathrm{d}}^{*}=\dot{i}_{\mathrm{q}}^{*}=0$. Under these conditions, current-flux error dynamic can be written as

$$
\begin{gathered}
\tilde{\mathbf{x}}_{1}=\mathbf{A}_{1} \tilde{\mathbf{x}}_{1}+\mathbf{B}_{1}(\mathrm{t}) \tilde{\mathbf{x}}_{2}, \\
\dot{\tilde{\mathbf{x}}}_{2}=\mathbf{A}_{2}\left(\mathrm{t}, \tilde{\mathbf{x}}_{1}\right) \tilde{\mathbf{x}}_{2},
\end{gathered}
$$

where $\tilde{\mathbf{x}}_{1}=\left(\mathrm{z}_{\mathrm{q}}, \tilde{\mathrm{i}}_{\mathrm{q}}\right)^{\mathrm{T}}, \quad \tilde{\mathbf{x}}_{2}=\left(\mathrm{z}_{\mathrm{d}}, \tilde{\mathrm{i}}_{\mathrm{d}}, \tilde{\psi}_{\mathrm{d}}, \tilde{\psi}_{\mathrm{q}}, \tilde{\tilde{\mathrm{i}}_{\mathrm{d}}}\right)^{\mathrm{T}}, \tilde{\psi}_{\mathrm{d}}=\psi_{\mathrm{d}}-\psi^{*}$, $\tilde{\psi}_{\mathrm{q}}=\psi_{\mathrm{q}}-$ are the flux tracking errors,

$$
\begin{aligned}
& \mathbf{A}_{1}=\left[\begin{array}{cc}
0 & \mathrm{k}_{\mathrm{ii}} \\
-1 & -\mathrm{k}_{\mathrm{iq} 1}
\end{array}\right], \\
& \mathbf{A}_{2}\left(\mathrm{t}, \tilde{\mathbf{x}}_{1}\right)=\left[\begin{array}{cccccc}
0 & \mathrm{k}_{\mathrm{ii}} & 0 & 0 & 0 \\
-1 & -\mathrm{k}_{\mathrm{id} 1} & \alpha \beta & \beta \omega & 0 \\
0 & \alpha \mathrm{L}_{\mathrm{m}} & -\alpha & \omega_{2} & 0 \\
0 & -\gamma_{1} \beta \omega & -\omega_{2} & -\alpha & -\gamma_{2} \beta \omega \\
0 & 0 & \alpha \beta & \beta \omega & -\mathrm{k}_{0}
\end{array}\right],
\end{aligned}
$$$$
\omega_{2}=\left(\omega_{0}-\omega\right), \mathrm{k}_{\mathrm{id} 1}=\gamma+\mathrm{k}_{\mathrm{id}}, \mathrm{k}_{\mathrm{iq} 1}=\gamma+\mathrm{k}_{\mathrm{iq}}, \mathrm{k}_{0}=\gamma+\mathrm{k}_{1} \text {. }
$$

In order to investigate the stability of the system (12) - (13) the following quadratic form for the flux subsystem (13) first considered

$$
\mathrm{V}=\left(\tilde{\Psi}_{\mathrm{d}}^{2}+\tilde{\Psi}_{\mathrm{q}}^{2}+\gamma_{1} \tilde{\mathrm{i}}_{\mathrm{d}}^{2}+\gamma_{2} \tilde{\overrightarrow{\mathrm{i}}}_{\mathrm{d}}^{2}\right) / 2
$$

The time derivative of (14) along the trajectories (13) can be derived as follows:

$$
\begin{gathered}
\dot{\mathrm{V}}=-\alpha\left(\tilde{\psi}_{\mathrm{d}}^{2}+\tilde{\psi}_{\mathrm{q}}^{2}\right)+\alpha\left(\mathrm{L}_{\mathrm{m}}+\gamma_{1} \beta\right) \tilde{\psi}_{\mathrm{d}} \tilde{\mathrm{i}}_{\mathrm{d}}+\gamma_{2} \alpha \beta \tilde{\psi}_{\mathrm{d}} \tilde{\tilde{\mathrm{i}}}_{\mathrm{d}} \\
-\gamma_{1} \mathrm{k}_{\mathrm{id} 1} \tilde{\mathrm{i}}_{\mathrm{d}}^{2}-\gamma_{2} \mathrm{k}_{0} \tilde{\tilde{\mathrm{i}}}_{\mathrm{d}}^{2} .
\end{gathered}
$$

Under the conditions

$$
\mathrm{k}_{\mathrm{id} 1}>\alpha\left(\mathrm{L}_{\mathrm{m}}+\gamma_{1} \beta\right)^{2} / 8 \gamma_{1}, \mathrm{k}_{0}>\alpha \gamma_{2} \beta^{2} / 8
$$

the form of (14) becomes a Lyapunov function satisfying conditions $\mathrm{V}>0, \dot{\mathrm{V}}<0$. Hence, according to Lyapunov stability criteria it can be concluded that the equilibrium point

$$
\left(\tilde{\mathrm{i}}_{\mathrm{d}}, \tilde{\psi}_{\mathrm{d}}, \tilde{\psi}_{\mathrm{q}}, \tilde{\tilde{\mathrm{i}}}_{\mathrm{d}}\right)=0
$$

is globally exponentially stable. From structural properties of subsystem (13) it can be concluded, that

$$
\tilde{\mathbf{x}}_{2}=\left(\mathrm{z}_{\mathrm{d}}, \tilde{\mathrm{i}}_{\mathrm{d}}, \tilde{\Psi}_{\mathrm{d}}, \tilde{\Psi}_{\mathrm{q}}, \tilde{\mathrm{i}}_{\mathrm{d}}\right)^{\mathrm{T}}=0 .
$$

As far as constant matrix $\mathbf{A}_{\mathbf{1}}$ is Hurwitz, nominal dynamic of subsystem (12) (if $\mathbf{B}_{\mathbf{1}}(\mathrm{t})=0$ ) is linear and exponentially stable. Matrix $\mathbf{B}_{\mathbf{1}}(\mathrm{t})$ is bounded and system (12), (13) can be viewed as composed of the exponentially stable subsystem (12) perturbed by a vanishing perturbation generated by subsystem (13). Hence equilibrium point

$$
\widetilde{\mathbf{x}}=\left(\tilde{\mathbf{x}}_{1}^{\mathrm{T}}, \tilde{\mathbf{x}}_{2}^{\mathrm{T}}\right)^{\mathrm{T}}=0
$$

is globally exponentially stable.

Remark 1. In contrast to solution [12], a correction term $\gamma_{1} \beta \omega \tilde{\mathrm{i}}_{\mathrm{d}} / \psi^{*}+\gamma_{2} \beta \omega \tilde{\tilde{\mathrm{i}_{\mathrm{d}}}} / \psi^{*}$ in equation (8) for the proposed controller is based on d-axis current estimation error $\tilde{\tilde{i}}_{d}$, while current tracking error $\tilde{i}_{d}$ is controlled at zero level using highgain PI-controller (10). This provides additional robustness properties with respect to stator resistance variations and inverter nonlinearities.

\section{B. Feedback linearizing voltage controller}

Taking in to account conditions (18) applied voltages becomes

$$
\begin{aligned}
& \mathrm{u}_{\mathrm{d}}=\mathrm{R}_{1} \mathrm{i}_{\mathrm{d}}^{*}-\sigma \omega_{0} \mathrm{i}_{\mathrm{q}}^{*}, \\
& \mathrm{u}_{\mathrm{q}}=\mathrm{R}_{1} \mathrm{i}_{\mathrm{q}}^{*}+\alpha \mathrm{L}_{\mathrm{m}}^{2} \mathrm{i}_{\mathrm{q}}^{*} / \mathrm{L}_{2}+\sigma \omega_{0} \mathrm{i}_{\mathrm{d}}^{*}+\mathrm{L}_{\mathrm{m}} \omega \psi^{*} / \mathrm{L}_{2} .
\end{aligned}
$$

Using (19) IG output power is computed as

$$
\mathrm{P}_{\mathrm{s}}=-\frac{3}{2}\left(\mathrm{R}_{1}\left(\mathrm{i}_{\mathrm{d}}^{* 2}+\mathrm{i}_{\mathrm{q}}^{* 2}\right)+\mathrm{R}_{2} \frac{\mathrm{L}_{\mathrm{m}}^{2}}{\mathrm{~L}_{2}^{2}} \mathrm{i}_{\mathrm{q}}^{*_{2}}+\frac{\mathrm{L}_{\mathrm{m}}}{\mathrm{L}_{2}} \omega \psi^{*} \mathrm{i}_{\mathrm{q}}^{*}\right) \text {. }
$$

According to (20) and under condition (18), the output power consist of the three components: active loses of the stator circuit (proportional to $\mathrm{R}_{1}$ ), active rotor loses the (proportional to $\mathrm{R}_{2}$ ) and input mechanical power

$$
\mathrm{P}_{\mathrm{m}}=\frac{3}{2} \frac{\mathrm{L}_{\mathrm{m}}}{\mathrm{L}_{2}} \psi^{* *} \mathrm{i}_{\mathrm{q}}^{*} \omega=\frac{3}{2} \frac{\mathrm{L}_{\mathrm{m}}}{\mathrm{L}_{2}} \psi \mathrm{i}_{\mathrm{q}} \omega=\mathrm{T} \omega
$$

where $\mathrm{T}-$ is electromagnetic torque.

Using equations (3), (4) we can derive [11]

$$
\begin{aligned}
& \dot{\mathrm{V}}_{\mathrm{dc}}=- \frac{1}{\mathrm{C}} \frac{3}{2 \mathrm{~V}_{\mathrm{dc}}}\left(\mathrm{R}_{1}\left[\frac{\psi^{* 2}}{\mathrm{~L}_{\mathrm{m}}^{2}}+\mathrm{i}_{\mathrm{q}}^{* 2}\right]+\mathrm{R}_{2} \frac{\mathrm{L}_{\mathrm{m}}^{2}}{\mathrm{~L}_{2}^{2}} \mathrm{i}_{\mathrm{q}}^{* 2}+\frac{\mathrm{L}_{\mathrm{m}}}{\mathrm{L}_{2}} \omega \psi^{* *} \mathrm{i}_{\mathrm{q}}^{*}\right)- \\
&-\mathrm{i}_{\mathrm{L}} / \mathrm{C},
\end{aligned}
$$

and voltage regulation dynamics became

$$
\begin{aligned}
\dot{\tilde{\mathrm{V}}}_{\mathrm{dc}}=- & \frac{1}{\mathrm{C}} \frac{3}{2 \mathrm{~V}_{\mathrm{dc}}}\left(\mathrm{R}_{1}\left[\frac{\psi^{* 2}}{\mathrm{~L}_{\mathrm{m}}^{2}}+\mathrm{i}_{\mathrm{q}}^{* 2}\right]+\mathrm{R}_{2} \frac{\mathrm{L}_{\mathrm{m}}^{2}}{\mathrm{~L}_{2}^{2}} \mathrm{i}_{\mathrm{q}}^{* 2}+\frac{\mathrm{L}_{\mathrm{m}}}{\mathrm{L}_{2}} \omega \psi^{*} \mathrm{i}_{\mathrm{q}}^{*}\right)- \\
& -\mathrm{i}_{\mathrm{L}} / \mathrm{C} .
\end{aligned}
$$

Let define desired voltage dynamics as a second order linear asymptotically stable system in the following form

$$
\begin{aligned}
& \dot{\tilde{\mathrm{V}}}_{\mathrm{dc}}=-\mathrm{k}_{\mathrm{v}} \tilde{\mathrm{V}}_{\mathrm{dc}}+\mathrm{x}_{\mathrm{v}}, \\
& \dot{\mathrm{X}}_{\mathrm{v}}=-\mathrm{k}_{\mathrm{vi}} \tilde{\mathrm{V}}_{\mathrm{dc}},
\end{aligned}
$$

where $\left(\mathrm{k}_{\mathrm{v}}, \mathrm{k}_{\mathrm{vi}}\right)>0$ are the proportional and integral gains of voltage controller.

Feedback linearizing voltage controller from (23) and (24) is given by the solution of nonlinear algebraic equation 


$$
\begin{gathered}
-\frac{1}{\mathrm{C}} \frac{3}{2 \mathrm{~V}_{\mathrm{dc}}}\left(\mathrm{R}_{1}\left[\frac{\psi^{* 2}}{\mathrm{~L}_{\mathrm{m}}^{2}}+\mathrm{i}_{\mathrm{q}}^{* 2}\right]+\mathrm{R}_{2} \frac{\mathrm{L}_{\mathrm{m}}^{2}}{\mathrm{~L}_{2}^{2}} \mathrm{i}_{\mathrm{q}}^{* 2}+\frac{\mathrm{L}_{\mathrm{m}}}{\mathrm{L}_{2}} \omega \psi^{*} \mathrm{i}_{\mathrm{q}}^{*}\right)- \\
-\mathrm{i}_{\mathrm{L}} / \mathrm{C}=-\mathrm{k}_{\mathrm{v}} \tilde{\mathrm{V}}_{\mathrm{dc}}+\mathrm{x}_{\mathrm{v}}, \quad \dot{\mathrm{x}}_{\mathrm{v}}=-\mathrm{k}_{\mathrm{vi}} \tilde{\mathrm{V}}_{\mathrm{dc}},
\end{gathered}
$$

as follows

$$
\begin{aligned}
& \mathrm{i}_{\mathrm{q}}^{*}=\frac{-\frac{\mathrm{L}_{\mathrm{m}}}{\mathrm{L}_{2}} \omega \psi^{*}+\sqrt{\left(\frac{\mathrm{L}_{\mathrm{m}}}{\mathrm{L}_{2}} \omega \psi^{*}\right)^{2}-4\left(\alpha \frac{\mathrm{L}_{\mathrm{m}}^{2}}{\mathrm{~L}_{2}}+\mathrm{R}_{1}\right) \rho}}{2\left(\alpha \frac{\mathrm{L}_{\mathrm{m}}^{2}}{\mathrm{~L}_{2}}+\mathrm{R}_{1}\right)}, \\
& \rho=\mathrm{R}_{1} \psi^{* 2} \mathrm{~L}_{\mathrm{m}}^{-2}+(2 / 3) \mathrm{V}_{\mathrm{dc}}\left(\mathrm{i}_{\mathrm{L}}+\mathrm{C}\left(-\mathrm{k}_{\mathrm{v}} \tilde{\mathrm{V}}_{\mathrm{dc}}+\mathrm{x}_{\mathrm{v}}\right)\right), \\
& \dot{\mathrm{x}}_{\mathrm{v}}=-\mathrm{k}_{\mathrm{vi}} \tilde{\mathrm{V}}_{\mathrm{dc}} .
\end{aligned}
$$

Controller block diagram is shown in Fig. 2.

For constant or slowly varying $\mathrm{V}_{\mathrm{dc}}^{*}, \mathrm{i}_{\mathrm{L}}, \psi^{*}-$ dynamics of the voltage control loop can be designed mach slower than current dynamics (12) providing the two-time scale separation, to justify common assumption for current fed IG control.

Under these conditions the system error dynamics is given by (24), (12) and allows for separated considerations of the two subsystems: voltage control loop (24) and flux-current error dynamics (12), (13).

System tuning is provided by selection of proportional and integral gains for voltage and current controllers as

$$
\mathrm{k}_{\mathrm{vi}}=\mathrm{k}_{\mathrm{v}}{ }^{2} / 2, \mathrm{k}_{\mathrm{ii}}=\left(\mathrm{k}_{\mathrm{i}}+\gamma\right)^{2} / 2
$$

Such tuning provides damping factor $\xi=\sqrt{2} / 2$ for each control loop. Natural frequency of undamped oscillations is given by $\omega_{\mathrm{ov}}^{2}=\mathrm{k}_{\mathrm{vi}}$ for voltage controller and $\omega_{0 \mathrm{i}}^{2}=\mathrm{k}_{\mathrm{ii}}$ for current controllers. The two-time scale separation between voltage and current loops is satisfied for condition $\omega_{0 \mathrm{i}}>(3-4) \omega_{\mathrm{ov}}$.

From this simplified stability analysis it follows that $\lim _{\mathrm{t} \rightarrow \infty} \tilde{\mathrm{V}}_{\mathrm{dc}}=0$, and therefore control objectives $\mathrm{CO} 1-\mathrm{CO} 3$ are locally achieved if $\left(\mathrm{L}_{\mathrm{m}} \omega \psi^{*} / \mathrm{L}_{2}\right)^{2}-4\left(\alpha \mathrm{L}_{\mathrm{m}}^{2} / \mathrm{L}_{2}+\mathrm{R}_{1}\right) \rho>0$.

Remark 2. For $\mathrm{i}_{\mathrm{L}}=$ const compensation term $\mathrm{i}_{\mathrm{L}}$ may be removed from feedback linearizing controller (26) leaving $\mathrm{i}_{\mathrm{L}}$ compensation for the integral action of the controller.

\section{EXPERIMENTAL RESULTS}

The experiments are carried out using the Rapid Prototyping Station (RPS). As shown in Fig. 3, the RPS includes: (1) Induction generator (see rated data in Appendix) coupled with induction motor which is used as primary mover; (2) $20 \mathrm{~A}$ and $380 \mathrm{~V}$ three-phase PWM controlled inverter, operated at $5 \mathrm{kHz}$ switching frequency; (3) Commutated load resistance $\mathrm{R}_{\mathrm{L}}$; (4) DSP TMS320F28335 controller which performs data acquisition, implements control algorithms with programmable tracing of selected variables; (5) Personal computer for processing, programming, interactive oscilloscope, data acquisition, etc. The motor speed is measured by a 1024 pulse/revolution optical encoder. The sampling time is $200 \mu$ sec. DC-link capacitance equal to $1000 \mu \mathrm{F}$.



Fig. 2. Voltage control system block diagram 


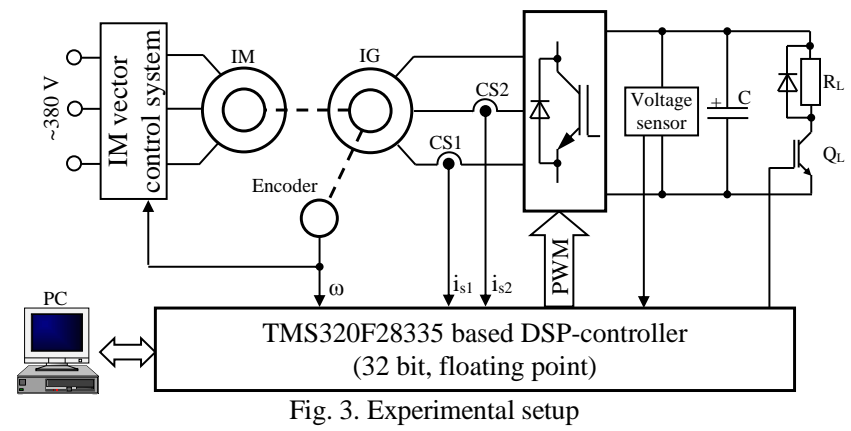

During all experiments, rotor speed is stabilized by industrial vector control system. In order to compare proposed solution with standard PI controller, described in [11], we eliminate compensation of load current $i_{L}$ at the first stage of experiments.

Tuning parameters are set to: controller (10), (11) $\mathrm{k}_{\mathrm{id}}=\mathrm{k}_{\mathrm{iq}}=800, \quad \mathrm{k}_{\mathrm{ii}}=\mathrm{k}_{\mathrm{iq}}^{2} / 4 ; \quad$ controller (8)-(11), (26) $\mathrm{k}_{\mathrm{v}}=125, \quad \mathrm{k}_{\mathrm{vi}}=\mathrm{k}_{\mathrm{v}}^{2} / 2$; controller [11] $\mathrm{k}_{\mathrm{v}}=0.2, \mathrm{k}_{\mathrm{v}_{\mathrm{i}}}=15$. Standard and developed controllers are tuned to provide the same performances when system operates at speed $140 \mathrm{rad} / \mathrm{s}$.

Comparative tests are performed for two constant speeds $\omega=140 \mathrm{rad} / \mathrm{s}$ and $\omega=100 \mathrm{rad} / \mathrm{s}$ using the same operation sequence:

- before the test DC-link voltage is charged to $330 \mathrm{~V}$, rotor speed is stabilized by primary mover;

- initial time interval $0 \ldots 0.3 \mathrm{~s}$ is used to excite the generator by applying flux reference trajectory reported in Fig. 4 with $\psi^{*}(0)=0.02 \mathrm{~Wb}$ and reached the value of $0.5 \mathrm{~Wb}$ (low flux level is used in order to prevent inverter voltage saturation during system start-up due to low level of $\mathrm{U}_{\mathrm{dc}}$ );

- starting at $\mathrm{t}=1 \mathrm{~s}$, voltage reference increases to level of $540 \mathrm{~V}$ with first derivative equal to $420 \mathrm{~V} / \mathrm{s}$;

- starting at $\mathrm{t}=2 \mathrm{~s}$, flux reference increases to $\psi^{*}=0.9 \mathrm{~Wb}$ in order to achieve IG operation with rated flux;

- at time $\mathrm{t}=3 \mathrm{~s}$ load current equal to $1.8 \mathrm{~A}$ ( $50 \%$ of rated value) is applied and at $\mathrm{t}=3.5 \mathrm{~s}$ is removed.

Experimental results for proposed voltage control algorithm (8)-(11), (26) are shown in Fig. 5. Flux and voltage tracking errors during simulation are depicted in Fig. 6.

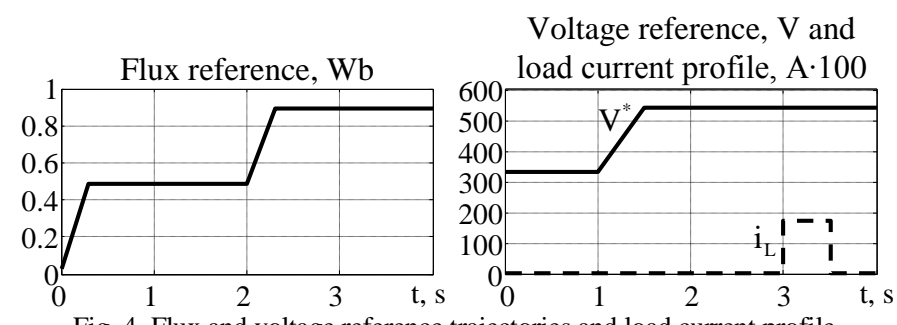

Fig. 4. Flux and voltage reference trajectories and load current profile

As it follows from transients is Fig. 5 and Fig. 6 proposed control algorithm provides asymptotic flux-voltage regulation. Experimental results are close to results of simulation.

In order to compare dynamic behavior of the standard and developed controllers at different speed we perform an additional test during IG operation with $\omega=140 \mathrm{rad} / \mathrm{s}$ and load equal to $50 \%$ of rated. Transients for both controllers at different speed are depicted in Fig. 7. From presented in Fig. 7 transients it follows that both controllers provides the same dynamic behaviour when system operates at speed $140 \mathrm{rad} / \mathrm{s}$. Performances of proposed controller are independent from generator speed. At the same time dynamics of standard controller deteriorates when $\omega=100 \mathrm{rad} / \mathrm{s}$. Dynamic error increases up to $12 \mathrm{~V}$.
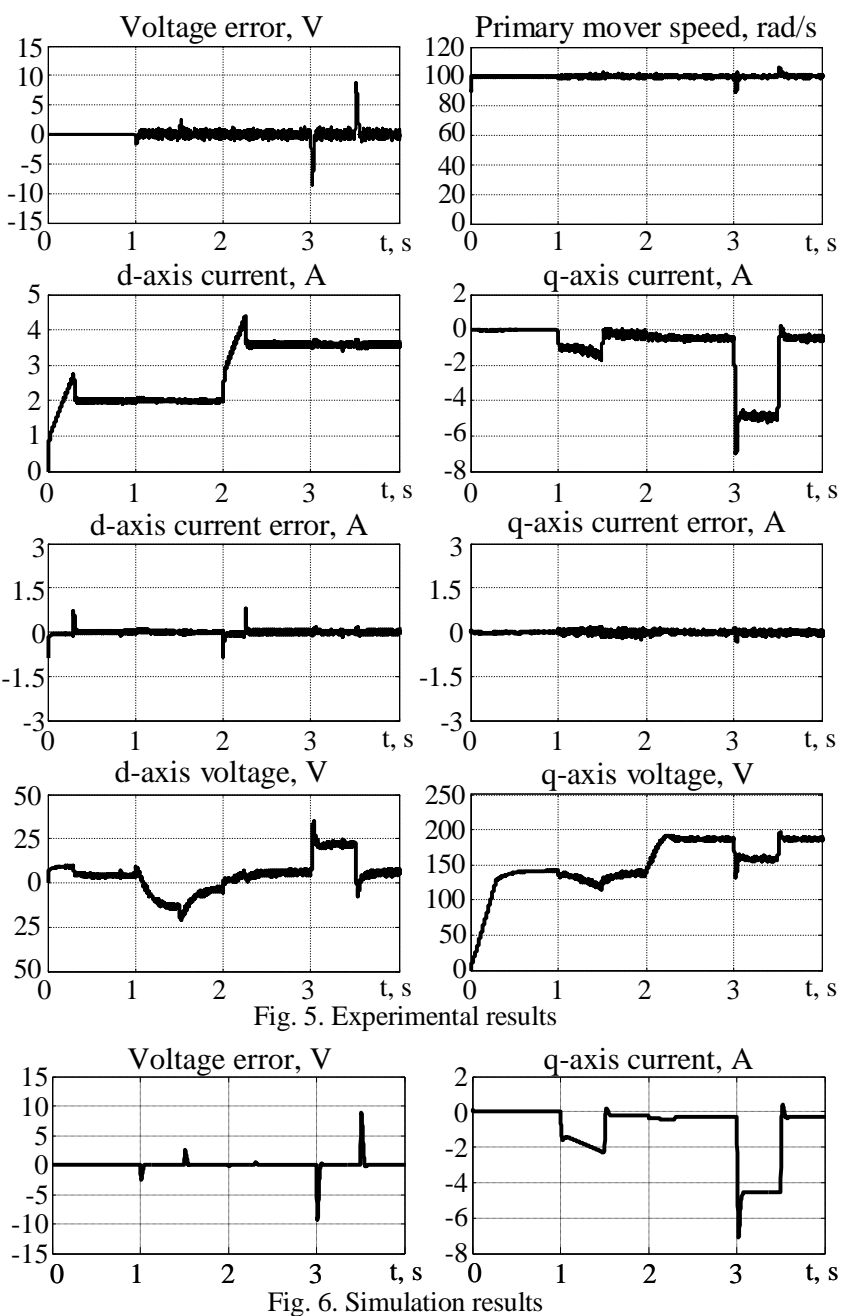

Transients with load current compensation in control algorithm (26) are shown in Fig. 8. Due to $i_{L}$ compensation dynamic voltage error is reduced to negligible level.

The next set of experiments is carried out in order to investigate robustness properties of controller (8)-(11), (26) with respect to rotor resistance variations. During these tests estimated value of $R_{2}$ in the controller was equal to $\hat{\mathrm{R}}_{2}=1.4 \mathrm{R}_{2}$. Such type of variation corresponds to worst case, when estimated rotor resistance used in the controller is grater than real value [13]. Experimental transients for standard and proposed controllers are depicted in Fig. 9. Note that during standard controller operation load duration was increased to $2 \mathrm{~s}$ in order to demonstrate steady state operation.

Comparison of the transients, reported in Figs. 9, 5 and 7, shows that improved indirect field-oriented controller demonstrates strong robustness properties with respect to 
rotor resistance variations. No significant difference can be noted in transients in nominal (Fig. 5, 7b) and perturbed (Fig. 9b) conditions. From Fig. 5 and 9b it follows that q-axis currents at steady state are at the same level.

From the other hand dynamic behavior of the standard controller significantly deteriorates: voltage regulation error has additional oscillations and q-axis current is increased to $32 \%$ at steady state in comparison to nominal conditions. As it shown in [12], [13], such current behavior leads to significant reduction of the system efficiency.
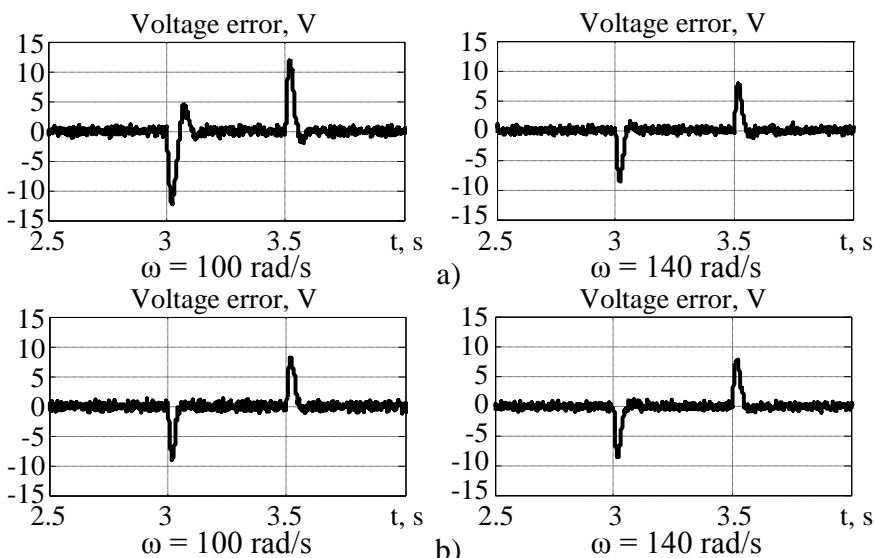

Fig. 7. DC-link voltage regulation at speed $140 \mathrm{rad} / \mathrm{s}$ and $100 \mathrm{rad} / \mathrm{s}$.

Experimental results: a) standard field oriented controller; b) proposed controller (8)-(11), (26)
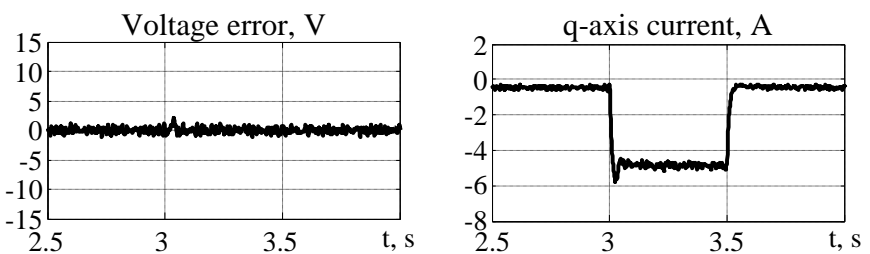

Fig. 8. DC-link voltage regulation at speed $100 \mathrm{rad} / \mathrm{s}$ using controller (8)-(11), (26) with $\mathrm{i}_{\mathrm{L}}$ compensation
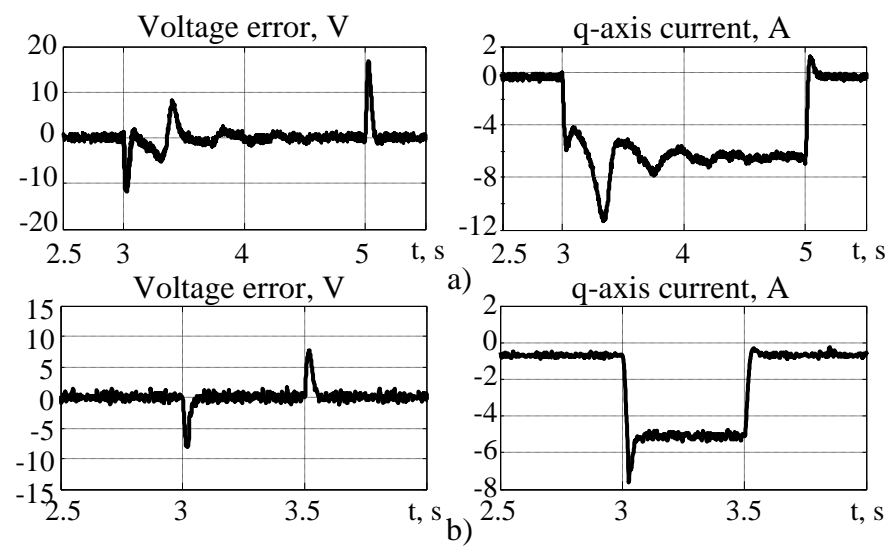

Fig. 9. Transients under rotor resistance variation: a) standard field oriented controller; b) proposed controller (8)-(11), (26)

\section{CONCLUSIONS}

A novel robust indirect field-oriented controller for induction generator has been designed. Nonlinear control algorithm guarantees local asymptotic voltage-flux regulation under variable speed and flux conditions. In contrast to existing solutions proposed controller provides system performances stabilization when speed and flux are varying. Robust with respect of rotor resistance variations flux controller provides improved voltage loop dynamics, robust stabilization of the torque current dynamics and therefore improved energy efficiency of the electromechanical conversion process.

The advantages of proposed solution with respect to standard control with PI voltage controllers are demonstrated by experiments. Designed controller is suitable for energy generation systems with variable speed operation.

\section{REFERENCES}

[1] R. O. C. Lyra, S. R. Silva, and P. C. Cortizo, "Direct and indirect flux control of an isolated induction generator," IEE Power Electronics and Drive Systems, pp. 140-145, 1995.

[2] D. Seyoum, M. F. Rahman, and C. Grantham, "Inverter supplied voltage control system for an isolated induction generator driven by a wind turbine," 38th IAS Annual Meeting Ind. Appl. Con. IEE Proc., vol. 1, pp. 568-575, Oct. 2003.

[3] T. Feehally and J.M. Apsley, "The Doubly Fed Induction Machine as an Aero Generator," IEEE Trans. Ind. Appl., vol. 51, no. 4, pp. 3462-3471, July-Aug. 2015.

[4] R. Cardenas, R. Pena, S. Alepuz, and G. Asher, "Overview of Control Systems for the Operation of DFIGs in Wind Energy Applications," IEEE Trans. Ind. Electron., vol. 60, no. 7, pp. 2776-2798, Jul. 2013.

[5] G. Iwanski, and W. Koczara, "DFIG-Based Power Generation System With UPS Function for Variable-Speed Applications," IEEE Trans. Ind. Electron., vol. 55, no. 8, pp. 3047-3054, Aug. 2008

[6] Seung-Ho Song, Shin-il Kang, and Nyeon-kun Hahm, "Implementation and control of grid connected AC-DC-AC power converter for variable speed wind energy conversion system," in Appl. Power Electronics Conference and Exposition, APEC '03. Eighteenth Annual IEEE, vol. 1, pp. 154-158, 9-13 Feb. 2003.

[7] S. Murthy, O. Malik, and A. Tandon, "Analysis of self-excited induction generators," IEE Proc. C Gener. Transm. Distrib., vol. 129, no. 6, pp. 260-265, 1982.

[8] E. Levi and Y. Liao."Rotor Flux Oriented Induction Machine as a DC Power Generator," European Power Electronics and Drives, pp. 1-8, 1999.

[9] S. Hazra and P. Sensarma, "DC bus voltage build up and control in stand-alone wind energy conversion system using direct vector control of SCIM," Electr. Power Appl. IEE Proc., vol. 2, pp. 2143-2148, Nov. 2008.

[10] A. Mesemanolis, C. Mademlis, and I. Kioskeridis, "HighEfficiency Control for a Wind Energy Conversion System With Induction Generator," IEEE Trans. Energy Convers., vol. 27, no. 4, pp. 958-967, Dec. 2012.

[11] S. Peresada, S. Kovbasa, S. Korol, N. Pechenik, N. Zhelinskyi, "Indirect Field Oriented Output Feedback Linearized Control of Induction Generator," in Proc. IEEE Int. Conf. on Intel. Energy and Power Systems, IEPS-2016, 07 - 09 Jun., Kyiv, 2015, pp. 187-191.

[12] S. Peresada and A. Tonielli, "High-performance robust speed-flux tracking controller for induction motor," Int. J. Adapt. Control Signal Process., vol. 14, pp. 177-200, 2000.

[13] S. Peresada, A. Tilli, and A. Tonielli, "Theoretical and experimental comparison of indirect field-oriented controllers for induction motors," IEEE Trans. on Power Electronics, vol. 18, no. 1, pp. 151-163, 2003

\section{APPENDIX}

IG parameters

\begin{tabular}{ll|lc} 
Rated output power & $1.9 \mathrm{~kW}$ & Stator resistance & $3.5 \mathrm{Ohm}$ \\
Rated phase voltage, rms & $220 \mathrm{~V}$ & Rotor resistance & $2.1 \mathrm{Ohm}$ \\
Rated phase current, rms & $5 \mathrm{~A}$ & Stator inductance & $0.2655 \mathrm{H}$ \\
Rated frequency & $50 \mathrm{~Hz}$ & Rotor inductance & $0.2655 \mathrm{H}$ \\
Number of pole pairs & 2 & $\begin{array}{l}\text { Magnetizing } \\
\text { inductance }\end{array}$ & $0.257 \mathrm{H}$
\end{tabular}

